\title{
Novas autorias em redes
}

\author{
New authorship's in networks
}

\author{
Fernando José de Almeida \\ Professor Doutor \\ Pontifícia Universidade Católica de São Paulo -PUC-SP. \\ São Paulo - Brasil. \\ fernandoalmeida43@gmail.com \\ (iD) Maria da Graça Moreira da Silva \\ Professora Doutora \\ Pontifícia Universidade Católica de São Paulo -PUC-SP. \\ São Paulo -Brasil. \\ mgraca.moreira@gmail.com \\ Maria Elizabeth Bianconcini de Almeida \\ Professora Doutora \\ Pontifícia Universidade Católica de São Paulo -PUC-SP. \\ São Paulo-Brasil. \\ bethalmeida@pucsp.br
}

\begin{abstract}
Resumo: O artigo analisa o caso "Projeto Monitoria EaD" e a coletânea "De Wuhan a Perdizes: trajetos educativos", ambos desenvolvidos no primeiro semestre de 2020. Inovadores, os dois projetos foram realizados por uma instituição de ensino superior para retomar as aulas em regime remoto após a suspensão das atividades presenciais decorrente da pandemia da Covid-19. Reuniram professores, alunos e egressos com comportamentos e características de uma "rede". Como resultados, as aulas, as leituras e as pesquisas foram recontextualizadas e ressignificadas, abrindo novos espaços de aprendizagem para professores e alunos. As variáveis, advindas das exigências de isolamento físico, possibilitaram um espaço de divulgação científica que dialogasse com os assuntos em voga que afetam a Educação formal. Emergiram novas autorias e parcerias. Os dois produtos resultaram na construção de uma "rede" democrática e inclusiva, que oportuniza a autonomia e o empoderamento dos integrantes.
\end{abstract}

Palavras-chave: Currículo. Ensino remoto. Inovação. Redes.

Abstract: The article analyzes the case "Project Monitoria EaD" and the collection "From Wuhan to Perdizes: educational paths", both developed in the first semester of 2020. Innovative, both projects were carried out by a higher education institution to take up classes on a regular basis, in a remote way, after the withdrawal of face-to-face activities due to the Covid-19 pandemic. They brought together teachers, students and graduates with the behavior and characteristics of a "network". As a result, classes, readings and research were recontextualized and reframed, opening new learning spaces for teachers and students. The variables, arising from the demands of physical isolation, enabled a space for scientific dissemination that dialogued with the current issues that affect formal education. New authorship and partnerships have emerged. Both resulted in the construction of a democratic and inclusive "network", which provides the members with autonomy and empowerment.

Keywords: Curriculum. Remote learning. Innovation. Network. 


\section{0 problema}

Este artigo apresenta, em forma de estudo de caso educacional, uma resposta local para uma crise civilizatória de grande amplitude. Considerou-se pertinente, portanto, apresentar um breve traçado do contexto atual que trouxe à tona questões históricas, políticas, econômicas e sanitárias que se acumulam até então no modelo da economia hegemônica mundial.

Não havia nenhuma possibilidade de se prever e conter a avalanche de emergências que caiu sobre toda a sociedade e, especialmente sobre a educação, a partir de fevereiro de 2020. Todos os países do mundo tiveram suas vidas em estado de suspensão e de espera angustiada. A Organização das Nações Unidas (ONU, 2020) divulgou que 776,7 mi de crianças e jovens, em 85 países do mundo, tiveram suas aulas e atividades educacionais suspensas a partir de 07/03/2020 número que muito se ampliou depois dessa data. Até para as agências de governança mundiais, como a Organização Mundial de Saúde (OMS), e para os sistemas públicos e privados de saúde em todo o mundo, a pandemia teve efeitos catastróficos e inexoráveis: é considerada uma "inflexão da história", com múltiplos e incertos cenários futuros.

O Brasil foi sacudido muito mais intensamente pela pandemia, pois, além do abalo econômico causado pela crise interna originada pelo isolamento físico, sofreu impactos da economia mundial. Tal abalo foi potencializado pelos desencontros contínuos das políticas públicas de saúde, do isolamento, da falta de rastreamento do contágio, assim como pelo negacionismo das orientações científicas e pela minimização irresponsável da mortandade que se anunciava, capitaneada pelo governo federal.

Diante desse contexto, a educação escolar se mobilizou com grande rapidez em alguns setores e ficou paralisada em outros. O caos se estabeleceu nas escolas públicas e as privadas, em doses quase iguais. Embora alguns Estados tenham se organizado mais rapidamente, a eficácia dos resultados nem sempre é comprovada.

Como veremos na publicação em tela (ALBUQUERQUE; RAMOS; RUPP, 2020), as decisões governamentais foram se esvaziando lentamente, mesmo que num esforço quase heroico por parte das escolas, nas figuras de seus professores e gestores, para manter as suas atividades. As duas escolas públicas estaduais da favela de Paraisópolis foram requisitadas para atender vítimas da pandemia. "No lugar da mobília característica das instituições, as escolas receberam leitos e biombos para separar os pacientes. Juntas, as escolas Etelvina e Maria Zilda passaram a oferecer 500 leitos para isolamento da comunidade acometida pelo coronavírus" (p. 153). O que isso significa para a comunidade do entorno é analisado no artigo do ebook, evidenciando um fenômeno social e educativo imprevisto para os padrões da sociedade. 
No município de São Paulo, algumas escolas particulares, sobretudo as que têm tradição no uso de tecnologias, agiram com rapidez, conseguindo minimizar perdas de energia nas relações de aprendizagem. Outras escolas, entretanto, menos preparadas pedagogicamente, fizeram movimentos incertos, com idas e vindas, muitas vezes pautadas pelas famílias que, como deveriam, assumiram parte do processo de ensinar e de inventar novas formas de acompanhar os serviços da escola.

A Pontifícia Universidade Católica de São Paulo (PUC-SP), objeto deste artigo, foi uma das instituições de ensino que enfrentou o desafio de continuidade das atividades educacionais por meio do ensino remoto. Nos seus 74 anos, a cultura da PUC-SP se apresenta como humanista, democrática e pautada por valores de uma educação transformadora. O enfrentamento do isolamento físico envolveu diversos setores da Universidade para viabilizar, rapidamente, infraestrutura tecnológica, programas de formação aos docentes, empréstimo de computadores, cartões de acesso aos alunos e acolhimento psicológico.

Em sintonia com a Instituição, imediatamente após o anúncio da pandemia, professores e alunos, de um dos Programas de Pós-graduação em Educação da PUC-SP, criaram o "Projeto Monitoria EaD” pelo qual teceram uma robusta parceria para a continuidade das atividades regulares em modalidade remota. Essa parceria formou uma "rede colaborativa", com funcionamento e características de uma rede de aprendizagem em serviço.

Um dos produtos desse complexo e rápido processo de enfrentamento da crise foi a produção colaborativa de um livro com registros do "Projeto Monitoria EaD” e dos conteúdos trabalhados nas aulas do semestre. Para alcançar tal finalidade, criou-se o projeto editorial de um ebook que, em 60 dias, produziu 28 artigos escritos por docentes e discentes, que desenharam coletivamente o projeto de trabalho. Os conteúdos ali trazidos foram o reflexo dos estudos, das pesquisas, das práticas docentes, das análises das políticas de saúde e do impacto da pandemia sobre os sistemas de ensino. O processo de aprendizagem para construir a publicação envolveu formalizações de convites à escrita; respeito às normas da ABNT; procedimentos editoriais, com equipe de pareceristas; elaboração de projeto gráfico, com criação de índices bibliográficos e direitos autorais de mais de 40 alunos envolvidos no projeto. No decurso deste artigo, serão pontuadas as reflexões e propostas daí emergidas e dos ganhos formativos para os alunos. Os temas foram enfatizados em quatro artigos do livro, ampliando a compreensão dos seus impactos na educação e iluminando as análises dos fenômenos educacionais e curriculares dos demais artigos. A seguir, destacam-se algumas das dimensões desse contexto. 


\section{$2 \mathrm{O}$ contexto}

No contexto da economia financista internacionalizada - que também dita as políticas nacionais -, as crises sempre aparecem como se fossem passageiras e contornáveis. A solução para as crises costuma se pautar no controle de gastos com os encargos do trabalho e cortes nos investimentos do Estado em Saúde, Educação e Cultura. Defendem, enganosamente, as reformas fiscais como as salvadoras da economia. Assim, sempre pagam o preço da crise o mundo do trabalho e as garantias sociais.

Bauman e Bordoni (2016), Harvey (2018), Marcial (2015) e Dowbor (2018) insistem nessas teclas, anunciando que ora as crises são forjadas para a própria existência do acúmulo do capital, ora de forma descontrolada pelas múltiplas variáveis que se operam fora dos planejamentos dos grandes conglomerados ou dos bancos de financiamento mundiais, como o FMI, Banco Mundial ou da própria OCDE. Portanto, as crises são forjadas para ajustar e ampliar os processos de concentração de riquezas - fenômeno crescente vertiginosamente na economia brasileira atual assim como a priorização da dita seriedade fiscal da economia descura total com a saúde e vida da população (De Bolle 2020).

Diz Marcial sobre mito do crescimento da economia (2015, p. 117):

Até 2030, estima-se que os países em desenvolvimento responderão por $57 \%$ do PIB mundial global. O crescimento dos países que não fazem parte da OCDE provavelmente continuará a superar o dos países que a compõem, mas a diferença vai diminuir nas próximas décadas. $\mathrm{O}$ crescimento médio de $7 \%$ a.a. daqueles países observado ao longo da última década é estimado a cair para aproximadamente $5.0 \%$ a.a. na década de 2020 . E para aproximadamente $2.5 \%$ a.a. até 2050 enquanto a previsão do crescimento dos países desenvolvidos é de 1.0 a 2,0\% em média.

Outra megatendência, conforme estudo de Marcial (2015, p. 197), é reforçada por novas pesquisas da mesma autora. Ela aponta como incerto que "até 2030 o Brasil pode tornar-se um exemplo de sucesso no desenvolvimento sustentável”. Ou seja, embora políticas de desenvolvimento sustentável possam ser fonte de riquezas e de qualidade do desenvolvimento nacional brasileiro, tal tendência não se realiza pela inépcia governamental no traçado de políticas com relação ao meio ambiente, assim como de implementação dessas políticas. A ocasião da pandemia afastou as mobilizações internas do Brasil para a defesa desta prioridade, mesmo que as devastadoras queimadas de 2020 tenham chamado a nossa atenção ao tema, assim como a de todo o mundo.

Além de perdermos, como nação, a autonomia para a defesa das riquezas do bioma interno, ainda se presencia uma política de degradação trazida pelo garimpo, pela desproteção dos povos indígenas e pelas plantações homogêneas. 
A economia liberal financista tecnológica aponta para a constrição do ciclo de desigualdades, como afirma Dowbor (2018, p. 29): “A concentração de renda e de riqueza no planeta atingiu níveis absolutamente obscenos. A financeirização dos processos econômicos há décadas se alimenta da apropriação dos ganhos de produtividade, essencialmente possibilitados pela revolução tecnológica". A afirmação de Dowbor se baseia, entre outros, nos seguintes dados: "Desde 2015, o 1\% mais rico detinha mais riqueza que o resto do planeta. Ao longo dos próximos 20 anos, 500 pessoas passarão mais de U\$2,1 trilhões para seus herdeiros - uma soma mais alta que o PIB da Índia, que tem 1, 2 bilhões de habitantes” (OXFAM, 2016, p. 2).

É importante compreender o contexto da economia e da política, apresentado brevemente neste artigo, para que o enfrentamento da pandemia não se limite ao tratamento das manifestações da doença e alcance a sua essência: o descaso com a vida, sobretudo a das populações vulneráveis, que sairão mais desgastadas e pauperizadas da pandemia. Os textos do livro refletem sobre o tema de forma inovadora, pois compreendem a saída da pandemia não como um 'novo-normal', mas como uma busca da superação das desigualdades entendendo-as como "anormais". Os estudos feitos nos cursos havidos no semestre sobre as saídas das centenas de pandemias sofridas na história da humanidade não nos trazem quase nenhuma esperança sobre uma mudança qualitativa (SCHEIDEL, W. 2020) das estruturas injustas.

\subsection{A pandemia nos rondará sempre}

Os vírus da Covid-19 não serão eliminados na pós-pandemia. Enfrentaremos mutações genéticas desses vírus e sofreremos diferentes degraus no seu enfrentamento e no reaparecimento da pandemia. No Brasil, o primeiro enfretamento se refere à produção da vacina adaptada às condições de aplicá-la a 210 milhões de pessoas. O segundo diz respeito à definição da prioridade de quem receberá a vacina: idosos ou crianças? O terceiro está relacionado ao apoio econômico e técnico da vigilância sanitária que acompanhará o rastreamento de contágio, bem como à forma de trabalho dos agentes de saúde do Sistema Único de Saúde (SUS), por exemplo. Os desafios se agravam com a tendência ao esvaziamento do compromisso do Estado com a saúde da população e, também, com a economia de recursos destinados aos atendimentos e programas sociais.

A crise atinge a escola e seu sistema com alto impacto. Em primeiro lugar, pelo clima favorável ao contágio, próprio da aglomeração escolar maciça. Em segundo, pela faixa etária de muitos educadores e funcionários que estão em idade de risco. Em terceiro, pela desigualdade de acesso aos meios digitais, sobretudo nas escolas públicas que sofrem com a falta de banda adequada à interação. Em quarto lugar, pela inadequação do trabalho online para a aprendizagem sólida e 
sistemática de crianças da Educação Infantil e dos primeiros anos da Educação Fundamental. A inicial fase de concentração e abstração em que se encontram as crianças faz com que o tempo de convívio, de lazer, de atividades e esportes lhes falte como o próprio ar que respiram, sendo-lhes mais importantes que o uso de tecnologias. As atividades cognitivas significativas não se desenvolvem, isoladamente, mas com uma complexa rede de compromissos culturais, lúdicos, de cuidados e de convívio.

Dados produzidos pelo Cetic.br, órgão de pesquisa do Comitê Gestor da Internet no Brasil - CGI (2019), trazem informações sobre as desigualdades digitais no espaço urbano, que nos permitem melhor analisar o contexto, assim como nortear as definições de políticas públicas. Afirma o texto sobre "Desigualdades Digitais no Espaço Urbano" (2019, p. 133):

Especialmente em alguns contextos, como o brasileiro, marcado por intensa
desigualdade, analisar os condicionantes da inclusão digital e as suas consequências é
trilha importante para repensar estruturas sociais, políticas e econômicas que contribuam
para o desenvolvimento.

A coexistência de grupos sociais com excelente acesso à banda (velocidade de acesso à internet), equipamentos e formação básica para o uso com grupos sociais com pouquíssima banda maior que $4 \mathrm{Mbps}$ (velocidade em mega bytes por segundo), com equipamentos de baixas resoluções e habitando em zonas de alta vulnerabilidade, tende a dar a impressão de que o acesso é suficiente. Além disso, os indicadores que apresentam média distorcem a realidade e a eficácia dos resultados sociais do uso da internet e do seu uso em celulares de baixos recursos. Entre 20122017 os indicadores de uso da internet "cresceram na ordem de 80\%, no que diz respeito ao acesso; dobrou a proporção daqueles que realizam mais atividades na rede e um quarto dos domicílios da cidade já tinha conexão superior a 4Mbps.” (CGI, 2019, p.135). Continua o texto da pesquisa: "ainda que a cidade tenha avançado de maneira mais acelerada que a média nacional, olhar para as métricas gerais do município esconde desigualdades internas importantes” (CGI, 2019, p. 136). E é sobre elas que este artigo quer iluminar a análise a ser feita durante a pandemia.

A ligeireza das soluções das políticas de educação dos Estados para as escolas nos faz supor que os alunos das escolas públicas vivem em territórios representados de formas favoráveis pelas estatísticas. No entanto, as decisões sobre a forma como devem ser as atividades remotas para jovens e crianças das escolas públicas, por exemplo, só poderiam ser realizadas com justiça se as conclusões fossem extraídas de indicadores combinados de exclusão social e exclusão digital. No caso de São Paulo, por exemplo, tais indicadores deveriam sair dos dados cruzados de suas 32 subprefeituras - trabalho feito pelo Cetic.br. Apenas com tais marcadores sociodemográficos bem definidos poder-se-ia detectar demandas pedagógicas e políticas direcionadas a públicos e locais específicos. 
Quatro dos artigos do livro "De Wuhan a Perdizes: trajetos educativos" apontam tais necessidades como parâmetros de construção das políticas de aulas remotas, uso de TV e atividades de aulas gravadas como forma adequada para enfrentar os desafios da educação escolar. Não se defende aqui a espera por condições ideais para que as atividades de aprendizagem mediadas pelas tecnologias na escola possam acontecer. A proposta é para que as políticas públicas partam das reais condições para o desenvolvimento de programas curriculares, com ampla participação de escolas, gestores e comunidades com suas realidades. Apenas com tais assentamentos responsáveis e analíticos da realidade local é que se pode construir currículos significativos e eficazes com as reais tecnologias disponíveis. Será isso possível? Aqui encontram-se os nós.

\subsection{Há esperanças?}

As forças vivas da sociedade, pressionadas pelos efeitos do isolamento, se analisam e se recriam. Quais as alternativas de saída? Que forças podem se aliar? Vamos aproveitar e fazer uma correção de rotas da sociedade que melhorem as condições para todos?

Entre as portas de saída está o equacionamento do papel da educação, das escolas e de seus efeitos potenciais associados. O que está em jogo para o justo papel da educação e das tecnologias no pós-pandemia é a organização de um novo pacto social. O capitalismo financista e tecnológico não atenderá os reclamos da desconcentração de renda, de redução de seus ganhos e de justiça salarial. O atual modelo de capitalismo não repetirá o capitalismo fordista (no início do século XX), que, mesmo concentracionário, desenhou um pacto social de distribuição de renda com os agentes sociais trabalhadores. O argumento lógico de Henry Ford era que se o trabalhador não tivesse renda sequer poderia comprar o próprio objeto por ele produzido. Além disso, mecanismos regulatórios também foram desenvolvidos com leis antitruste, que minimizaram os efeitos discrepantes da distribuição de rendas advindas do trabalho e deram uma sobrevida ao capitalismo de caráter mais distributivo, no pós-segunda guerra mundial. No entanto, a lógica fordista foi superada pelo mercado de compra internacional do século XXI, promovido, viabilizado e acelerado pelo capitalismo dos fluxos digitais de moedas virtuais.

Nesse cenário, cabe à educação formal escolar, sobretudo, trabalhar com conhecimentos de várias origens epistemológicas e finalidades para criar dispositivos curriculares de análise e interpretação da realidade do mundo em que se vive. Cabe, ainda, à escola criar formas de permitir que as novas gerações, que passaram uma enorme proporção de sua vida isoladas, possam entender onde entram e como poderão participar deste mundo. Devem saber que o mundo novo do século XXI não é mais o do homem empreendedor de si mesmo, de um egoísmo encapsulado, mas o de 
um homem social e que viverá em grupos heterogêneos, partilhando um futuro que não terá sentido sem solidariedade, sem redes. São necessárias redes sociais cuja finalidade apontem para a dimensão política da vida com participação dos bens produzidos para todos.

O conhecimento escolar e o currículo exigirão uma visão interdisciplinar, com o aporte de todas as ciências, da arte, da educação do corpo, da matemática, da literatura, da história, da cartografia, das línguas, da filosofia, das ciências sociais e políticas. A educação será habitada por valores republicanos e terá a democracia participativa como construção histórica em sua morada.

Os problemas que se associam ao vírus trazem um momento de parada à análise e reflexão para os educadores, e uma ocasião da ressignificação de seu trabalho no seio da sociedade, evidenciado no trabalho curricular da escola. E é nesse contexto de ressignificar o trabalho dos educadores que surge a discussão sobre a criação da rede virtual de aprendizagem do "Projeto Monitoria" e a produção do livro "De Wuhan a Perdizes: trajetos educativos". A migração do presencial ao virtual, para alguns, acena para uma antecipação do futuro, com educação ubíqua, espaços e tempos flexíveis, compondo-se com os formais tempos escolares. Para outros, em especial para os professores mais maduros, mostra-se como uma distopia (DUSSEL, 2020) que levará a uma perda da dimensão pública e comum da escolarização e com consequências nefastas inestimáveis.

No entanto, defende este artigo que a constituição da "rede" se apresenta como resposta ou como possibilidade para ampliar as interações, os fluxos democráticos de comunicações, enfatizando sua natureza eminentemente democrática, aberta e emancipatória (CAPRA, 2001, MARTINHO, 2003), uma vez garantidas a equidade de condições de acesso e não políticas baseadas em abstrações das médias de acessibilidade. A "rede" pode ser entendida como um processo para responder às demandas de descentralização e democracia do mundo contemporâneo e o exercício da autonomia (MARTINHO, 2003). O que se argumenta neste artigo é que a pandemia nos trouxe à reflexão potencializada pelas redes, mas só a partir de conteúdos e propostas que permitam a inovação da essência do convívio humano, hoje devastador e pouco solidário.

\subsection{As redes}

De que rede falamos? O individualismo é um bunker obsoleto, e como tal deve ser abandonado, nos alertou Maffesoli (2000). O autor aponta como alternativa a "tribo", com sua multiplicidade do "eu" e a sua ambiência comunitária na qual o destaque passa a ser o que nos une e não o que nos separa. $\mathrm{Na}$ tribo, está presente um ethos comunitário formado pelo conjunto de expressões que apontam uma subjetividade comum: aquilo que é compartilhado. 
Para fugir do individualismo e construir um novo padrão de convívio social, uma das respostas pode estar nas redes. Não na Rede das Redes, a internet, ou na rede tecnológica que conecta diversos computadores. Em tais redes os objetivos são o consumo e a obtenção de dados de vigilância sobre todos. Existem redes de diversas ordens. Entretanto, neste trabalho tratamos de rede de pessoas, ou redes com finalidades sociais. Nesse sentido, a rede se apresenta como um projeto deliberado de organização da ação humana (CAPRA, 2001), o que presume a conexão e o relacionamento entre indivíduos em sua dimensão de cidadãos e não apenas fechados em bolhas de grupos homogêneos.

As redes são estruturas plásticas, não lineares, dinâmicas e indeterminadas. Sua configuração é flexível e regida por mecanismos de autorregulação, à maneira dos sistemas adaptativos e complexos (MARTINHO, 2003). As redes possuem fluidez, movimento e mudam sua centralidade: o ponto que está no centro e a periferia podem se alternar de acordo com o fluxo das relações. Ora crescem, ora diminuem, desenham diferentes formatos e densidades, os nós se juntam em diferentes configurações de acordo com as interações que se estabelecem entre os nós. A rede é acêntrica e não hierárquica por natureza, o que confere a ideia de igualdade entre os pontos. No entanto, não basta a infraestrutura aberta das redes, mas importa que os projetos que circulam na rede toquem o bem comum, as dimensões do convívio e a melhoria da vida.

Martinho (2003) aponta como características de uma rede social: o que une os integrantes são os valores e objetivos estabelecidos em comum; a adesão é voluntária, assim depende da vontade de cada integrante em participar ou seguir um projeto; cada integrante possui autonomia e reconhece a autonomia do outro; cada um exerce suas habilidades de interação como um grupo maduro, assumindo a coautoria e a coliderança; a rede pode se desdobrar em diversos níveis ou segmentos autônomos.

A infraestrutura tecnológica não é, nem garante a organização e o funcionamento de uma rede social, mas possibilita que as interações se realizem mais rapidamente e que os fluxos "fluam". A rede social não é sinônimo de "Faceboook", "whats app" ou similares, mas essas ferramentas tecnológicas potencializam as redes a assumirem as características fluidas, ubíquas, instigantes e complexas pelas quais são conhecidas.

Por isso, é a visão mais ampla de sociedade, de seu compromisso com as questões da cidade e do planeta que distinguem as redes sociais, virtuais e democráticas daquelas redes sociais meramente de relacionamentos socioafetivos, de espetacularização dos indivíduos e de fenômenos domésticos e de curtidas. A reflexão sobre redes poderia se alongar, o que não é compatível com a extensão deste artigo. Para sintetizar o destaque que se pretende conferir à rede, citamos: "É 
possível construir formas de organização social inovadoras, baseadas em princípios democráticos, inclusivos, emancipadores e que busquem a sustentabilidade" (MARTINHO, 2003, p. 2). O método e a descrição dos casos são explicitados a seguir.

\section{Metodologia}

A metodologia empregada neste artigo, conforme as pesquisas, projetos e teorias desenvolvidos pela Linha de Pesquisa Novas Tecnologias na Educação, é de abordagem qualitativa e apresenta um estudo de caso educacional do "Projeto Monitoria EaD", assim como do livro "De Wuhan a Perdizes".

Cabe aqui retomar que o estudo de caso educacional, segundo Bassey (2003, p.58), "é uma investigação empírica conduzida dentro dos limites localizados no tempo e no espaço, versa sobre aspectos relevantes ou significativos de uma atividade educacional, programa ou sistema e, geralmente, decorre num contexto natural e dentro de uma ética de respeito às pessoas. Assim, o relato do estudo de caso educacional apresentado neste artigo é de característica narrativa e busca dar luz ao caso sobre a prática do "Projeto Monitoria EaD" e do livro em tela.

O projeto foi desenvolvido no ano de 2020, em razão da interrupção das aulas pela necessidade do afastamento físico decorrente da pandemia da Covid-19. Os sujeitos são 18 "pesquisadores-monitores", mestrandos e doutorandos, três docentes-orientadores e 12 docentesparceiros que integram o corpo docente do mesmo Programa. Além desses, 10 egressos também compuseram a rede, participando do grupo de monitores, assim como do conselho de pareceristas do livro "De Wuhan a Perdizes: trajetos educativos" e de seus escritores.

\section{A migração}

A LP NTE refletiu sobre sua trajetória na pesquisa e formação de professores por meio de "cursos a distância para os sistemas públicos de educação e nos valemos da vivência na formação de monitores para apoiar o trabalho remoto dos professores nas atividades das disciplinas" (ALMEIDA, M., 2020, p. 171, grifo nosso). Assim, na migração de um para outro território, do físico para o virtual, foram levados os anos de estudos, reflexões, pesquisas e projetos desenvolvidos pelos docentes e discentes, seus resultados, e a concepção de educação, currículo e de tecnologia voltadas para a transformação social.

Para enfrentar a realidade e a continuidade das atividades acadêmicas que possibilitassem a cada professor atuar segundo seu estilo, à luz das pesquisas anteriores, foi retomada a função do "monitor", que, a princípio, tinha o papel de sugerir estratégias e ferramentas para os professores 
usarem em seus ambientes virtuais de modo a contemplar as intenções pedagógicas, os diferentes estilos de trabalho e preferências do docente responsável pela disciplina. Trata-se, assim, de um trabalho conjunto em que o monitor assessora o docente no planejamento, processo de apropriação pedagógica das tecnologias em uso e na consecução de sua prática pedagógica.

Assim,

Foram constituídas duplas entre professor e monitor de modo a criar vínculos entre eles e essa dupla atua em seu território criado no ambiente virtual e nas salas de web conferência, ao tempo que cria estórias que falam das relações estabelecidas nesses territórios, dos avanços, dificuldades e desafios (ALMEIDA, M., 2020, p. 172).

\subsection{O acionamento da rede}

Martinho (2003) aponta que as redes usualmente são silenciosas, estão lá, ocultas (CAPRA, 2001), submersas, e somente vêm à tona quando acionadas, ou melhor, quando chamadas ou convocadas para uma ação. Eis que a pandemia as chamou para a ação.

A rede se iniciou com uma chamada aos discentes que pesquisam sobre o tema tecnologias e educação, preferencialmente com fluência tecnológica, para, a um só tempo, estabelecer parcerias com docentes e com seus pares discentes, de forma a acolhê-los, familiarizá-los com o acesso e com a cultura da educação online, no processo de "migração forçada", do presencial ao virtual em questões de dias (CHENDO, 2020).

No primeiro momento, por volta de uma a três semanas do início do afastamento físico na instituição de ensino, a atenção foi voltada para "não deixar ninguém para trás”, incluindo "todos" nos ambientes virtuais, contornando as dificuldades de acesso e as idiossincrasias dos sistemas tecnológicos. Para tais ações, pesquisadores-monitores e docentes-orientadores participaram de oficinas sobre o uso das plataformas adotadas para as aulas remotas.

A maneira pela qual o grupo se constituiu foi reveladora em fundamentos para a formação de educadores: democracia, participação, empoderamento, resolução de problemas, acolhimento, trabalho colaborativo e outros conceitos inerentes à vivência acadêmica (OLIVEIRA et al., 2020, p. 56).

Os docentes-parceiros se envolveram na aprendizagem das ferramentas e na transformação de seu planejamento para a realidade que ora se apresentava. O trabalho de atuação do processo de monitoria e a dinâmica de construção do livro envolviam os alunos e docentes na mesma metodologia de produção e reflexão sobre as práticas. Ramos, Barragan e Masetto (2020) descrevem o percurso: $1^{\circ}$ ) transformar o plano de curso presencial para a distância, assumindo os objetivos com os estudantes; $2^{\circ}$ ) desenvolver uma interação entre os atores (professor, monitores e alunos); $3^{\circ}$ ) estudar, analisar e utilizar as plataformas além de outras metodologias participativas; $4^{\circ}$ ) planejar e desenvolver, em conjunto, um processo de avaliação que incluísse o desempenho dos 
alunos, através de feedbacks contínuos; o desempenho do professor e monitores e a adequação do programa que estava sendo implementado.

Nesse sentido, a preocupação colocada por Dussel (2020) de que as inovações tecnológicas que alteram antigas práticas podem "trazer perda da dimensão pública e comum da escolarização e com consequências inestimáveis" não se mostrou presente nos trabalhos aqui analisados.

\subsection{Nós coaprendizes}

Num segundo momento, variável dentre a terceira e a oitava semana, a energia voltou-se para compreender melhor como se poderia incentivar novas práticas pedagógicas que passaram a caracterizar a educação remota. Mesmo que vários monitores e docentes já tivessem experiência em educação a distância, essa era uma situação inusitada - nem presencial, nem a distância. Foram construídos novos sentidos nessa parceria docente-discente, com um alimentando o outro por meio de laços fortes de interações nas redes.

O planejamento e as estratégias de aprendizagem, assim, foram sendo reconstruídos entre as parcerias, trazendo à tona os conceitos de coaprendizagem que, como explicitam Barros e Okada (2013), enfatizam as mudanças nos papéis de professores e alunos para parceiros no processo de aprendizagem, na construção de significados, na compreensão e na criação colaborativa de conhecimentos, tal como a rede de monitores neste artigo. Os coaprendizes, segundo as autoras, exercem seus papéis por meio do "compartilhamento coletivo de feedbacks e comentários, coorquestração de sua produção e socialização em rede do processo de coaprendizagem, bem como dos caminhos de aprendizagem aberta colaborativa" (BARROS; OKADA, 2013, n.p.).

\section{$4.3 \mathrm{Na}$ rede e com a rede}

Ao longo dos quatro meses (março-julho) dessa trajetória, não foram esquecidas as tensões que marcaram e marcam a realidade brasileira e as perdas de vidas. Na rede, foram constantes os espaços de apoio, empatia e solidariedade. Foram registrados momentos em que a crise do dia a dia de confinamento, a angústia de não vislumbrar saídas fáceis para a equidade ou justiça educacional, as ausências dos alunos nas salas de aula, as incertezas, a espera, as inúmeras demandas profissionais e o próprio sentido da vida ocuparam os espaços e tempos necessários para o diálogo, para o afeto e a solidariedade. A morte e o internamento de parentes interferiram nas relações do grupo. O humano se tornou o mobilizador dessa rede. Ao tratar o sentimento de pertencimento e a solidariedade que se estabelecem entre os integrantes de uma comunidade, Maffesoli (2000) 
destaca que a motivação se vincula às relações emocionais, uma verdadeira "comunidade emocional".

\subsection{Todos os nós}

O terceiro momento apontou a necessidade de debater em rede a proposta de acompanhamento e avaliação: o que avaliar, como avaliar e autoavaliar-se. Reviveu-se, com a rede, a teoria na prática: a adoção dos princípios da avaliação formadora e processual. Cada docente, com sua turma, desenvolveu a avaliação segundo critérios acordados, sem, no entanto, desconsiderar o momento histórico, o contexto, os alunos e as aprendizagens. Desse modo, concretizou-se a ação de avaliar em rede.

\subsection{Ampliando a rede}

O quarto momento se caracterizou pela ampliação da rede, uma de suas características naturais, uma vez que é fluida, includente e, por isso, tende a se expandir. Alguns novos monitores integraram-se à rede ao longo do tempo, já sem ter a especificidade de pesquisar tecnologias e educação e sem a necessidade de pré-requisito de tanta fluência no uso das plataformas, uma vez que a rede já se retroalimentava e um acolhia, ensinava e aprendia com os demais. A rede se modificou. Uns a deixaram e outros a integraram; foram estabelecidas novas parcerias e os nós hiperconectados; os pares mais experientes se incumbiram da formação e/ou atualização dos ingressantes e, num curto período, a centralidade se alternou da periferia para o centro.

\subsection{Rede de autorias}

A autonomia, o empoderamento e a emancipação dos integrantes da rede desvelaram novas cartografias curriculares desenhadas em coautorias, por meio da leitura crítica do mundo com os instrumentos que dispunham no contexto da pandemia pela Covid-19 e a rede entendeu que já havia chegado o tempo de colocar no mundo suas palavras.

Entre laços mais fracos ou mais fortes, os integrantes da rede se juntaram em pequenos grupos dentro da própria rede, estabelecendo diferentes conexões. Foi o momento pedagógico em que todos entenderam ser apropriado compartilhar as trajetórias educativas vivenciadas a fim de contribuir com educadores e instituições de ensino em preparação para assumir práticas de ensino remoto durante o afastamento físico ou no retorno às aulas, na implementação da educação híbrida. Tais constatações vão se evidenciar, também, nos artigos do livro analisado. 


\subsection{A criação de uma publicação como forma republicana de pedagogia}

Dentro dos contextos e dos conceitos apresentados, a produção do livro "De Wuhan a Perdizes" "abriu um horizonte para as novas ideias aqui apresentadas e que emergiram do Projeto Monitoria EaD. O horizonte da cooperação ampliou-se com o convite à escrita que nasceu de uma potência interna entre professores e alunos de posicionamento sobre o momento e a função da educação neste cenário. As aulas, as leituras, as pesquisas e novas realidades oriundas da pandemia receberam um novo sopro de vida, de indignação e de utopias. Tais variáveis trouxeram à tona a possibilidade de criar um espaço de divulgação científica urgente e que dialogasse com os assuntos que afetam o vasto campo da Educação e fez emergir novas autorias na própria rede.

Os objetivos traçados para a publicação foram dar oportunidade a: publicações mais ágeis sobre temáticas da atualidade, para a circulação do debate; iniciação à escrita de alunos, aproveitando trabalhos das aulas e de parte de suas pesquisas; ampliação de possibilidades de publicação conjunta entre professores, alunos e egressos, tornando-se elemento de divulgação entre futuros candidatos ao Programa.

No mês de maio, já com a rede em movimento, foi realizado o convite para que se abrisse a todos os professores tal campo de manifestação de seus trabalhos e reflexões. O teor do convite, como uma forma de participação coletiva, representando um esforço de todos foi a tônica da mobilização dos autores, bem como a possibilidade de publicações virtuais, mais ágeis, em forma de ebook com cuidadoso acabamento gráfico e distribuído gratuitamente.

Ficou claro que uma publicação como esta pode gerar a produção de novos espaços, envolvendo educadores para debates, interlocuções e temas conjuntos, com ênfase na aproximação com redes públicas, que foram objeto de alguns artigos citados.

Para a produção e editoria do livro foi criado um comitê editorial, coordenado pelos três docentes-orientadores e três doutorandas integrantes da rede de pesquisadores-monitores e um comitê científico, composto por dez egressos do Programa, com experiências ligadas a cursos de pós-graduação em distintas instituições.

Assim, o livro digital trata, sob o ponto de vista da educação, dos aspectos inesperados e tão comuns aos seres humanos em situações de hecatombes, como guerras, quedas de Estados, pandemias e devastações, que não são estranhos à nossa breve história sobre a terra. 


\section{Considerações}

A questão que incitou essa temática como uma experiência inovadora que emergiu durante a pandemia se relaciona com a constituição de uma "rede". Este artigo destaca o "Projeto Monitoria EaD" que se articulou como uma "rede", assim como a construção do livro "De Wuhan a Perdizes". Ambos os projetos tiveram o sentido de uma tessitura de valores de democracia participativa, de bem comum e de ampliação da coesão social. Caracterizaram-se pela relação teoriaprática, colocando os conceitos e as pesquisas em ação. As atividades da rede se encorparam e floresceram para além de seu objetivo inicial: criar parcerias docente-discente para que todas as disciplinas ingressassem nos ambientes virtuais para continuidade das atividades. Os conteúdos da formação da rede se mostraram tão importantes como as tecnologias que as articulam. O sentido não vem do gradeado da rede, mas das suas finalidades. Essa mobilização foi construindo sentidos e significados, distinguindo-se como uma vivência inovadora que integra currículo, tecnologias e autoria, envolvendo todos os docentes, discentes e egressos do Programa, assim como valendo-se de múltiplas plataformas de comunicação e das redes sociais. À medida que as redes se formavam - nos ambientes de aprendizagem e na construção do livro - os conteúdos de seus trabalhos ficavam mais evidentes como valores humanistas e sensíveis com relação ao cenário mundial, nacional e das turmas de centenas de alunos que sentiam em suas famílias as perdas e o peso das desigualdades sociais.

As ações da rede alcançaram sua culminância no mês de junho de 2020, quando todos chegaram ao cerne de seus trabalhos e se reconheceram como autores, constatação visibilizada na publicação do livro eletrônico, cujos conteúdos refletiam uma visão crítica sobre a história das pandemias, sobre as soluções e explicações dadas tantas vezes pelos interesses econômicos em detrimento da vida e da justiça.

Assim, este artigo considera que uma "rede" democrática, inclusiva, pode abrir caminhos à autonomia e ao empoderamento para a transformação necessária e para o exercício de uma educação emancipatória.

As discussões caóticas e dirigidas pela grande mídia sobre o que está por vir facilitam a proliferação de enganosos "novos normais". O mundo antes da pandemia não era normal. As desigualdades, a violência, o tratamento da natureza, assim como o consumo individualista não podem ser chamados de normais. E por isso o termo "novo normal” não é novo nem é normal.

O olhar para a história e para a forma como a humanidade passou pelas pestes que a atacaram evidencia um cenário pouco solidário, em que o impacto e a mortandade resultantes da ação do vírus são esquecidos rapidamente. O chamado "novo normal" expôs-nos à reflexão de 
que a vida se dava na anormalidade, naturalizada como correta pelos seres humanos, o que pode levar à retomada de uma sociedade injusta e não emancipatória. A educação escolar e, por conseguinte, o currículo, podem vir a ocupar espaços de destaque nas discussões sobre o que seria essa redefinição de sociedade e de projeto de nação, necessariamente pautada numa "ética da responsabilidade" para as projeções de um futuro necessário, o único possível para a continuidade da vida na Terra. Sempre é bom trazer à lembrança que nós precisamos dela e não o contrário. Sem o homem, a Terra segue. Mesmo sem a nossa vida, a Terra continua.

\footnotetext{
${ }^{1}$ Livro disponível gratuitamente para download em: https://www.pucsp.br/educ/downloads/trajetos_educativos.pdf. Acesso em 20 de novembro de 2020.
}

\section{Referências}

ALBUQUERQUE, J.G.; RAMOS, C. A S.; RUPP, L. L. O inesperado: de escola a centro de acolhimento pandemia e suas urgências para além do ideal. In: ALMEIDA, F. J.: ALMEIDA, M. E. B.; SILVA, M. G. (Orgs.). De Wuhan a perdizes: trajetos educativos. São Paulo: EDUC, 2020. p. 152-163.

ALMEIDA, M.E.B. A crise educacional gerada pelo Covid 19e as tecnologias: ontem, hoje e caminhos para o futuro. In: ALMEIDA, F. J.; ALMEIDA, M. E. B.; SILVA, M. G. (Orgs.). De Wuhan a perdizes: trajetos educativos. São Paulo: EDUC, 2020. p. 164-178.

BASSEY, M. Case study research in educational setting. Philadelphia: Open University Press, 2003.

BARROS, D. M.; OKADA, A. Os estilos de coaprendizagem para as novas características da educação (3.0). In: VIII INTERNATIONAL CONFERENCE ON ICT IN EDUCATION, 1516 Jul. 2013, Braga, Portugal.

BAUMAN, Z.; BORDONI, C. Estado de Crise. Tradução: Renato Aguiar. Rio de Janeiro: Zahar, 2016.

CAPRA, F. A teia da vida: Uma nova compreensão científica dos sistemas vivos. São Paulo: Cultrix/Amana-Key, 2001.

CGI. Comitê Gestor da Internet no Brasil. Desigualdades digitais no espaço urbano: um estudo sobre o uso da internet na cidade de São Paulo. São Paulo: NIC.br, 2019.

CHENDO, M. Educación 2020: los migrantes forzados. Iberoamérica Social. Disponível em: https://iberoamericasocial.com/educacion-2020-los-migrantes-forzados/. Acesso em: 20 set. 2020.

DE BOLLE, Monica Baungarten. Pilhas de areia: rupturas. Rio de Janeiro: Intrínseca, 2020. 


\section{Dialogia}

ALMEIDA, Fernando José de; SILVA, Maria da Graça Moreira da; ALMEIDA, Maria Elizabeth Bianconcini de. Novas autorias em redes

DOWBOR, L. A era do capital improdutivo. 2. ed. São Paulo: Outras Palavras, 2018.

DUSSEL, I. La clase en pantuflas. Conversatorio virtual con Inés Dussel. Canal ISEP. 23 abr. 2020. Vídeo (1h19min). Disponível em:

https://www.youtube.com/watch?v=6xKvCtBC3Vs\&feature=youtu.be. Acesso em: 20 set. 2020.

HARVEY, D. A loucura da raz̃ão econômica: Marx e o capital no século XXI Tradução: Artur Renzo. São Paulo: Boitempo, 2018.

OLIVEIRA, F. et al. Os caminhos da monitoria nas práticas educativas remotas. In: ALMEIDA, F. J.; ALMEIDA, M. E. B.; SILVA, M. G. (Orgs.). De Wuhan a perdizes: trajetos educativos. São Paulo: EDUC, 2020. p. 54-63.

ONU. News Bruxelas (Bélgica). Jornal da ONU, 17 de março de 2020. Podcast. Disponível em: https://news.un.org/pt/audio/2020/03/1707612. Acesso em: 20 set. 2020.

OXFAM Brasil. Uma economia para os 99\%. 2017. Disponível em:

https://www.oxfam.org.br/justica-social-e-economica/forum-economico-de-davos/umaeconomia-para-os-99/. Acesso em: 20 set. 2020.

MAFFESOLI, M. O tempo das tribos: o declínio do individualismo nas sociedades de massa. 3. ed. Rio de Janeiro: Forense Universitária, 2000.

MARCIAL, E. (Org.) Megatendências mundiais 2030: o que entidades e personalidades internacionais pensam sobre o futuro do mundo? Contribuição para um debate de longo prazo para o Brasil. Brasília: Ipea, 2015.

MARTINHO, C. Redes: uma introdução às dinâmicas da conectividade e da auto-organização. Brasília: WWF Brasil, 2003.

RAMOS, C.; BARRAGAN, L.; MASETTO, M. Educação a distância: monitores e professor, equipe responsável pela disciplina. In: ALMEIDA, F. J.; ALMEIDA, M. E. B.; SILVA, M. G. (org.). De Wuhan a perdizes: trajetos educativos. São Paulo: EDUC, 2020. p. 14-21.

SCHEIDEL, W. Violência e a história da desigualdade: da idade da pedra ao século XXI. Tradução: Vera Ribeiro. Rio de Janeiro: Zahar, 2020.

Recebido em: 29 set. 2020/ Aprovado em: 26 nov. 2020

Cite como

(ABNT NBR 6023:2018)

ALMEIDA, Fernando José de; SILVA, Maria da Graça Moreira da; ALMEIDA, Maria Elizabeth Bianconcini de. Novas autorias em redes. Dialogia, São Paulo, n. 36, p. 176-192, set./dez. 2020. Disponível em: https://doi.org/10.5585/dialogia.n36.18317.

\section{American Psychological Association (APA)}

Almeida, F. J. de., Silva, M. da G. M. da., \& Almeida, M. E. B. de. (2020, set./dez.). Novas autorias em redes. Dialogia, São Paulo, 36, p. 176-192. https://doi.org/10.5585/dialogia.n36.18317. 